\title{
Política social focalizada e ajuste fiscal: as duas faces do governo Lula
}

Graça Druck

Universidade Federal da Bahia (UFBA)
Luiz Filgueiras

Universidade Federal da Bahia (UFBA)

\section{Política social focalizada e ajuste fiscal: as duas faces do governo Lula}

Resumo: Este texto tem por objetivo analisar a natureza e as principais características da política social do governo Lula, evidenciando a sua estreita relação com a política econômica liberal-ortodoxa legada do governo anterior como uma 'herança maldita', mas mantida e aprofundada pelo novo governo. Portanto, mais do que esmiuçar todos os detalhes e dimensões dessa política social, o objetivo é o de apreender o seu conteúdo e significado político-econômico maior, a partir daquilo que lhe é central e que a define politicamente, inclusive em termos simbólicos, qual seja: o programa focalizado de combate à pobreza denominado Bolsa Família.

Palavras chave: política social focalizada, Bolsa Família, precarização, ajuste físcal, política econômica.

\section{Focused Social Policy and Fiscal Adjustment: Two Sides of the Lula Government}

Abstract: The purpose of this article is to analyze the nature and principal characteristics of the Lula government's social policy, revealing its close relationship with the liberal-orthodox economic policy inherited from the previous government as a 'cursed legacy', but maintained and extended by the new government. Therefore, more than reviewing all the details and dimensions of this social policy, the purpose is to analyze its content and broader political-economic meaning, considering its central and politically defining element, even in symbolic terms: the Family Grant program to combat poverty.

Key words: focused social policy, Family Grant, precariousness, fiscal adjustment, economic policy. 


\section{Introdução}

O presente artigo apresenta uma análise da natureza e das principais características da política social do governo Lula, em particular o programa focalizado de combate à pobreza denominado Bolsa-Família, demonstrando que:

a) A natureza e o conteúdo desse tipo de política social só podem ser desvendados, em sua plenitude, quando devidamente articulados ao modelo econômico vigente, em particular à sua política econômica e aos seus impactos sociais. Isto significa dizer que, para além de seus efeitos (reais) amenizadores da miséria e do sofrimento dos mais pobres, considerar essa política apenas em si mesma, fora dessa articulação, implica, necessariamente, em reificála - tendo como resultado final a despolitização do debate sobre a questão social e a legitimação da estratégia política liberal.

b) $\mathrm{O}$ caminho das comparações pontuais e/ou descontextualizadas, entre o governo Lula e o governo Cardoso, que procura identificar 'avanços' quantitativos positivos, em geral milimétricos, na política social do primeiro, é o caminho mais curto para a despolitização do debate e o acobertamento dos liames que ligam esses dois governos - inclusive com o rebaixamento programático do que deve ser o conteúdo de uma política social de esquerda.

c) O conteúdo da política social do governo Lula, no essencial, é o mesmo da política social do governo anterior, apesar dos discursos em contrário, que tentam dignificá-la e diferenciá-la - apresentando-a como uma política (supostamente) articulada a medidas de natureza estrutural de combate à pobreza.

d) Esse tipo de política social, que se originou da preocupação das instituições multilaterais, em particular o FMI e o Banco Mundial, com a instabilidade política dos países da periferia do capitalismo - em muito agravada com a implementação das políticas e reformas econômicas liberais -, passou a ser recomendada enfaticamente por essas instituições a partir, principalmente, do final dos anos 1990, após a ocorrência de sucessivas crises econômicas.

Além dessa Introdução, esse texto é composto por mais quatro seções. Na primeira, demarca-se a historicidade das políticas sociais; na segunda seção, caracteriza-se o Modelo Liberal Periférico (MLP) e analisa-se a política econômica do governo Lula; na terceira, analisa-se a política social do governo Lula - a sua natureza, o seu alcance e a sua limitação; e finalmente, na Conclusão, sintetiza-se o caráter flexível e volátil dessa política.

\section{Política social: universalização versus focalização}

A origem e motivação das políticas sociais datam do século 19 , quando a hegemonia do capitalismo industrial e as revoluções burguesas criaram uma acirrada disputa entre o campo dos direitos políticos (cidadãos livres e iguais) e o campo do mercado e da economia liberal sustentados no direito de propriedade e na relação de exploração ilimitada do trabalho assalariado. Do ponto de vista da ideologia liberal, a sociedade é produto de escolhas e responsabilidades individuais, a partir das quais se estabelecem acordos e contratos. No entanto, desde os primórdios do capitalismo, as lutas operárias expuseram as condições precárias de trabalho, fruto da relação desigual entre os indivíduos e derivadas da subordinação e intensa exploração dos trabalhadores, que, aos poucos, foram conquistando, algum tipo de amparo legal e estatal, através da legislação fabril - ainda que esta tenha sido, sistematicamente, desrespeitada na prática pelos industriais.

A "invenção do social" (DONZELOT, 1994) ou a (metamorfose da) "questão social" (CASTEL, 1995) demonstram a realidade e a necessidade históricas do 'social', no sentido da criação de uma política ou uma ação para por limites, para regular e estabelecer direitos sociais, a fim de reduzir a voracidade do capitalismo e da 'mão livre do mercado'. É o reconhecimento da existência do social para preservar a própria sociedade. Trata-se, portanto, de se constituir uma 'autoridade pública', através do Estado, que garanta a sobrevivência da sociedade e de seus cidadãos, a começar pelo direito ao trabalho e ao emprego, assim como as demais necessidades para se viver socialmente. Reside nessa condição iminente, de esfacelamento da sociedade, a origem dos serviços públicos e das instituições públicas capazes de desempenhar o papel de mediadoras e limitadoras da dominação do capital sobre o trabalho e, conseqüentemente, de redutoras da assimetria destas forças no mercado.

No século 20, a partir dos anos 30, e principalmente no pós-Segunda Guerra Mundial, os países mais desenvolvidos da Europa viveram uma experiência que se tornou referência para todo o mundo. Uma época em que se constituiu o 'Estado de Bem-Estar Social', resultado de um pacto entre as organizações políticas e sindicais dos trabalhadores (através da social-democracia) e os capitalistas. Pacto este alicerçado, de um lado, numa melhor distribuição de renda e dos ganhos de produtividade e, de outro, na aceitação da ordem do capital. Nesse período criou-se a possibilidade de implementação de políticas sociais como instrumento de regulação do mercado, sendo estabelecido um conjunto de direitos sociais universais (emprego, moradia, educação, saúde, transporte, etc.) reivindicados pelos trabalhadores e garantidos pelo Estado, tornando, desta forma, o capitalismo menos devastador. 
É contra essa experiência das políticas sociais universais, garantidas pelo Estado de Bem-Estar Social, que surgem as primeiras iniciativas de cunho neoliberal, em 1947, na reunião de Mont Pèlerin (ANDERSON, 1995) - que negam o 'social' reconhecido e regulado pelo Estado e propõem a sociedade livre 'regulada' pelo mercado e pelas escolhas e iniciativas dos indivíduos. Proposição derrotada à época e que, por quase 40 anos, não teve força para se contrapor às políticas de bem-estar social. $\mathrm{E}$, mesmo nos países da periferia, em especial na América Latina, as políticas sociais universais inspiraram os modelos adotados, como no caso brasileiro, através do populismo getulista e do Estado corporativo, resultando no que alguns autores denominam de "fordismo periférico ou incompleto".

É a partir dos anos 1980, para os países desenvolvidos, e dos anos 1990 no caso do Brasil, que o neoliberalismo se impõe e consegue se tornar hegemônico no âmbito mundial. Embora com diferentes fisionomias e configurações em cada região ou país, tem em comum alguns valores centrais retomados do liberalismo, em especial uma ação dirigida para a "destituição do social" (IVO, 2001), ou seja, uma política de destruição dos direitos sociais conquistados pelas lutas dos trabalhadores, dentre eles aquele mais elementar: o direito ao emprego. Nesta investida, as políticas sociais vão perdendo apoio, a universalidade do acesso aos serviços públicos vai sendo reduzida nos países centrais, levando ao enfraquecimento dos Estados de Bem-Estar Social na Europa.

Nos países da América Latina, nos quais não se estabeleceu plenamente as políticas sociais universais, nem mesmo a "cidadania do fordismo" (MOTA, 1991), as diretrizes do Banco Mundial passaram a ser respeitadas, defendidas e aplicadas - com a substituição crescente dos poucos direitos sociais conquistados pelas "políticas de combate à pobreza". Neste contexto, se implementam as chamadas políticas focalizadas, cuja lógica perversa foi sintetizada por Ivo (2001, p. 67-68) da seguinte forma:

No âmbito do tratamento da questão 'social', retira-se o caráter universalista dos direitos, especialmente aqueles securitários, para uma política que se orienta gradativamente para uma avaliação dos atributos pessoais (os mais aptos, os realmente pobres, os mais pobres entre os pobres) e morais (aqueles que 'devem' receber a assistência). Por outro lado, o caráter fragmentado da incorporação de diferentes segmentos das classes trabalhadoras ao sistema (baseado num sistema de direitos, restrito à camada assalariada) gerou uma reconversão perversa de benefícios-obrigações em privilégios. Hoje, o que é dever de proteção do Estado (para todos) reconverte-se, supostamente e de forma perversa, em indivíduos-perversos-imo- rais ao sistema, responsáveis pela miséria dos outros. [...] Assim, tecnifica-se a questão social, que passa a se constituir em programas subordinados aos gastos públicos e sociais, ou seja, da solução da crise fiscal, dependente, portanto, dos fluxos de capital para pagamento da dívida, num quadro de redução dos gastos sociais (se comparados ao patamar das décadas anteriores).

De fato, a política social focalizada, de combate à pobreza, nasce e se articula umbilicalmente às reformas liberais e tem por função compensar parcial, e muito limitadamente, os estragos socioeconômicos promovidos pelo MLP e suas políticas econômicas, reconhecidas pelo Banco Mundial (BANCO MUNDIAL, 2006) baixo crescimento econômico, pobreza, elevadas taxas de desemprego, baixos rendimentos, enfim, um processo generalizado de precarização do trabalho.

Uma política social apoiada num conceito de pobreza restrito, que reduz o número real de pobres, suas necessidades e o montante de recursos públicos a serem disponibilizados - adequando-os ao permanente ajuste fiscal a que se submetem os países da região, por exigência do FMI e do capital financeiro (os mercados) para garantir o pagamento das suas respectivas dívidas públicas. Portanto, uma política social que se define e se caracteriza por ser a contra-face dos superávits fiscais primários.

Uma política social de natureza mercantil, que concebe a redução da pobreza como um 'bom negócio' e que transforma o cidadão portador de direitos e deveres sociais em consumidor tutelado, através da transferência direta de renda, e cuja elegibilidade, como participante desses programas, subordina-se a critérios "técnicos" definidos ad hoc a depender do governo de plantão e do tamanho do ajuste fiscal numa operação ideológica de despolitização do conflito distributivo.

Uma política social que, pela sua própria origem e natureza, busca se implementar e se tornar hegemônica a partir da negação dos direitos e das políticas sociais universais, através de um discurso que ataca diretamente a seguridade e a assistência social públicas - aposentadorias, pensões, seguro desemprego, etc. - bem como a universidade pública e as políticas de subsídios ao consumo de bens básicos, como no caso da energia elétrica.

Uma política social que divide, canhestramente, os trabalhadores em categorias do tipo: miseráveis, mais pobres, pobres, não pobres e privilegiados - estes últimos identificados como aqueles que têm acesso à seguridade social incompleta e limitada, própria dos países da periferia do capitalismo, em particular da América Latina. Uma política social que enclausura o conflito distributivo na base da pirâmide social e é compatível com o empobrecimento e redução das chamadas classes médias e o processo de polariza- 
ção das desigualdades na distribuição de renda (SALAMA, 2006) - ambos produtos do período de vigência do MLP.

Enfim, uma política social que desloca a disputa entre capital e trabalho, própria das sociedades capitalistas, para o âmbito interno da classe trabalhadora, transformando-a assim num conflito distributivo que opõe os seus vários estratos: assalariados com rendimentos mais elevados versus mais reduzidos, trabalhadores qualificados versus não-qualificados, trabalhadores formais versus informais, participantes versus não participantes da seguridade social, trabalhadores do setor publico versus do setor privado, etc. Todas elas, clivagens reais ou imaginárias, acentuadas ou criadas pelo capital e sua política, que fragmentam a classe trabalhadora e estimulam e açulam a disputa entre os seus diversos segmentos.

\section{0 modelo liberal-periférico no Brasil e suas políticas macroeconômicas}

No Brasil, desde o início dos anos 1990, vive-se um processo de constituição, aprofundamento, consolidação e ajuste de um mesmo modelo econômico (liberal-periférico), que começou a se esboçar a partir do governo Collor (1990-1992) e tomou sua forma mais acabada no governo Lula (2003-2006). O conjunto das reformas que conformaram esse novo modelo econômico implicou profundas transformações (FILGUEIRAS, 2006a) em pelo menos quatro dimensões inter-relacionadas;

1) As relações capital/trabalho sofreram uma inflexão radical que, ao mudar a correlação de forças a favor do primeiro, implicou a desestruturação do mercado de trabalho e um processo generalizado de precarização do trabalho - cuja face mais visível é o crescimento do desemprego aberto de caráter estrutural, o aumento da informalidade e o enfraquecimento dos sindicatos. Adicionalmente, essa inflexão passou a colocar em questão todos os direitos sociais e trabalhistas conquistados pela classe trabalhadora desde os anos 30 do século passado - em particular através do ataque sistemático à Consolidação das Leis do Trabalho (CLT) e à Constituição de 1988.

2) A relação entre as distintas frações do capital foi reconfigurada, com o capital industrial perdendo a sua condição de hegemonia política e de líder do processo de desenvolvimento e da dinâmica macroeconômica. Em seu lugar assumiu o capital financeiro - nacional e internacional - e uma fração do capital industrial que se financeirizou organicamente. Nessa nova configuração, o sistema financeiro passou por um processo de concentração enorme e acentuou a sua natureza parasitária, continuando a operar, essencialmente, no financiamento da divida pública.

3) A inserção internacional, feita de forma passiva, a partir da abertura comercial e financeira da economia e tendo por objetivo imediato o combate à inflação, agravou a vulnerabilidade externa do país, tornando a sua dinâmica macroeconômica mais dependente dos ciclos do comércio internacional e dos movimentos de curto prazo do capital financeiro.

4) A estrutura e o funcionamento do Estado se redefiniram, através da privatização de suas empresas e de várias reformas de caráter liberal - como a da previdência social e a quebra do monopólio estatal do petróleo. Além disso, a partir de 1994, em virtude da lógica macroeconômica intrínseca ao Plano Real, o Estado foi fragilizado financeiramente ainda mais, através do crescimento vertiginoso da dívida pública, que implicou a perda de sua capacidade de investimento e restringiu decisivamente a política social.

No entanto, a política e a dinâmica macroeconômicas - expressões mais aparentes e imediatas do modelo econômico - não se mantiveram exatamente as mesmas ao longo de todo o período (1994-2006).

Na verdade, pode-se traçar uma linha divisória, que distingue dois momentos na evolução desse modelo econômico a partir de um acontecimento bem preciso: a crise cambial deflagrada em janeiro de 1999, logo no início do segundo governo Cardoso. Esse fato implicou a mudança da política econômica e um ajuste político-econômico do modelo, com implicações importantes para a sua dinâmica macroeconômica e o tratamento da questão social. Nesse segundo período, as políticas focalizadas, já desenhadas e iniciadas no primeiro governo Cardoso, passaram a assumir uma dimensão cada vez maior (FILGUEIRAS, 2006b).

O governo Lula (2003-2006), por sua vez, não moveu um milímetro para alterar a essência do modelo de desenvolvimento - caracterizado, sobretudo, pela dominação da lógica financeira - nem, tampouco, a política macroeconômica que herdou do governo anterior. Ao contrário; deu continuação às reformas liberais - através da implementação de uma reforma da previdência dos servidores públicos que abriu espaço para o capital financeiro. $\mathrm{Na}$ mesma direção, iniciou um processo para reformar a legislação sindical e sinalizou para uma reforma das leis trabalhistas, com o intuito de aprofundar a flexibilização já em curso. Além disso, logo no início do governo, alterou a Constituição, para facilitar, posteriormente, o encaminhamento da proposta de independência do Banco Central. Posteriormente, aprovou a lei de falências e a lei das chamadas parcerias público-privado (PPP), com o intuito de desencadear 
uma nova fase das privatizações, agora abarcando a infra-estrutura futura do país - uma vez que a política de superávits primários reduz drasticamente a capacidade de investir do Estado (FILGUEIRAS, 2006b).

Na política macroeconômica, o governo Lula elevou os superávits fiscais primários para mais de 4,25\% do PIB. Por isso, juntos, como se pode constatar no Quadro 1, o segundo governo Cardoso e o governo Lula (até julho de 2006) propiciaram ao capital financeiro um montante de mais de um trilhão de reais de juros da dívida pública e pagaram, com os superávits primários, $\mathrm{R} \$ 468,5$ bilhões (correspondendo a $8 \%$ e $8,2 \%$ do PIB, respectivamente, no segundo governo Cardoso e no governo Lula). Apesar disso, a dívida pública foi acrescida, entre 1995 e julho de 2006, em mais R $\$ 817,1$ bilhões - condicionando, decisivamente, os gastos sociais, conforme se verá na próxima seção.

\section{A política social do governo Lula}

A grande desigualdade (patrimonial e de renda) e o elevado grau de pobreza existente no Brasil remetem, em sua origem mais longínqua, à formação econômicosocial do país, calcada na escravidão e no latifúndio. Permanentemente atualizada após a implantação do trabalho assalariado, essa realidade sobreviveu a vários períodos de sua história econômica e política, chegando aos dias atuais determinada, cada vez mais, pelo binômio propriedade fundiária-capital financeiro.

Nesse processo, a questão social, transformada em uma questão política a partir dos anos 1930 pelo varguismo, se explicitou e se estruturou a partir das políticas trabalhistas, tendo como uma das características essenciais um alcance limitado - restrita a alguns segmentos de trabalhadores do setor urbano.

Quadro 1 - Juros, superávit e crescimento da dívida

\begin{tabular}{l|rrr}
\hline \multicolumn{1}{c|}{ Período } & $\begin{array}{c}\text { Juros } \\
\text { (R\$ Bilhões) }\end{array}$ & $\begin{array}{c}\text { SFP } \\
\text { (R\$ Bilhões) }\end{array}$ & $\begin{array}{c}\text { Aumento da DP } \\
\text { (R\$ Bilhões) }\end{array}$ \\
\hline $1995-1998$ & 211,4 & $-6,5$ & 217,9 \\
$1999-2002$ & 511,1 & 165,4 & 345,7 \\
$2003-2006 / 07$ & 557,1 & 303,6 & 253,5 \\
Total & $1.068,2$ & 462,5 & 817,1 \\
\hline
\end{tabular}

Fonte: Banco Central do Brasil em: <www.bcb.gov.br>.

Desse modo, analisar as políticas econômica e social do governo Lula, a partir dessa percepção, significa distinguir, de um lado, o primeiro governo Cardoso (19951998) - período mais duro de implantação do novo modelo, no qual a dominância do capital financeiro, no interior do bloco de poder dominante, pode ser qualificada como inconteste e estrita; e, de outro, o segundo governo Cardoso (1999-2002) e o governo Lula (2003-2006) - no qual a hegemonia do capital financeiro persiste, mas com uma maior acomodação dos interesses de outras frações do capital participantes do bloco de poder, especialmente os seus segmentos exportadores.

Do ponto de vista estrutural, o que assegura e explica a linha de continuidade entre o segundo governo Cardoso e o governo Lula, com a manutenção do mesmo modelo econômico, da mesma política macroeconômica e, não surpreendentemente, da mesma política social, é a permanência, ao longo de todo o período, do mesmo bloco de poder dominante, construído a partir do inicio dos anos 1990 sob os escombros do Modelo de Substituição de Importações (MSI) - bloco este que sofreu acomodações no começo do segundo governo Cardoso, mas que manteve como hegemônico, na sua direção política, o capital financeiro. Além disso, também foi fundamental, para a ausência de mudanças significativas entre os dois governos, o processo de 'transformismo' político trilhado por Lula e pelo Partido dos Trabalhadores (PT).
Os trabalhadores rurais não se constituíram em sujeitos do pacto populista e só vieram a se incorporar à seguridade social muitos anos depois.

Com o fim do regime militar e a elaboração de uma nova Constituição (1988), numa década de vigor dos movimentos sociais e sindical - com a criação do PT, da Central Única dos Trabalhadores (CUT) e do Movimento dos Trabalhadores Rurais Sem Terra (MST), conseguiu-se inserir na lei maior do país reivindicações históricas desses movimentos, dando um estatuto legal para instauração de uma seguridade social de fato universal.

No entanto, não houve tempo para se avançar muito nessa direção. A vitória, implementação e consolidação do neoliberalismo a partir dos anos 1990 passaram a colocar em questão, primeiramente, a ampliação dos direitos inseridos na nova Constituição e, posteriormente, todo e qualquer direito - sempre em nome de ajustes fiscais (déficit público) e monetários (combate à inflação). É isso que explica o ataque político-ideológico sistemático à Constituição de 1988, implementado pelas classes dominantes, desqualificando-a como 'populista', 'irresponsável' e 'desfocada da realidade econômicofinanceira do Estado e do país' - com o patrocínio, nestes últimos 16 anos, de inúmeras emendas que vêm, paulatinamente, desfigurando-a.

A partir da elaboração e implementação do Plano Real, e ainda em sua fase preliminar no final de 1993, 
as políticas universais inscritas na Constituição sofreram um violento golpe, com a criação de um mecanismo de desvinculação entre receitas e despesas, que passou a vigorar a partir de 1994 - permitindo, a partir daí, que os sucessivos governos fizessem uso de $20 \%$ do total de impostos e contribuições federais de acordo com as suas conveniências políticas. Portanto, reduzindo, de fato, os recursos originalmente previstos para a área social. Esse mecanismo, que tomou o nome à época de Fundo Social de Emergência, foi mais tarde rebatizado como Fundo de Estabilização Fiscal e hoje é conhecido como Desvinculação de Receitas da União (DRU). Através de sucessivas medidas provisórias, todos os governos, inclusive o governo Lula, renovaram a validade desse perverso mecanismo. Em 2007, deverá ser renovado pelo segundo governo Lula.

Nesse contexto de ajuste fiscal permanente, colocado em prática a partir do segundo governo Cardoso, e mantido durante o governo Lula, a política social foi se transformando em sinônimo de política social focalizada, voltada para os mais pobres e miseráveis - com a criação de inúmeros programas de complementação de renda. Implementada ainda de forma tímida pelos governos de Cardoso, tal política vai ser ampliada e aprofundada pelo governo Lula, que lhe dá continuidade sob os aplausos do Banco Mundial.

De fato, essa política tem limites dados pelo modelo de desenvolvimento vigente, articulando-se funcionalmente a ele como uma espécie de contra-face da política macroeconômica ortodoxa calcada em enormes superávits fiscais primários. O Quadro 2, referente à execução orçamentária do período 2000-2005, discrimina o total de gastos do Governo Federal agrupando-os, segundo a sua finalidade, em três rubricas: encargos especiais (juros e serviços da dívida pública, transferências e outras despesas financeiras), gastos sociais totais (previdência e assistência social, educação, saúde, trabalho, cultura, desporto e lazer, habitação e saneamento) e outros (administração e planejamento, desenvolvimento regional, defesa nacional e segurança pública, agricultura, transporte, energia, recursos minerais, judiciário, legislativo, etc.).

O constrangimento dos gastos sociais e de outros gastos, em virtude do enorme serviço da dívida pública e outros encargos financeiros, é evidente: com pequenas variações ano a ano, a proporção de gas- tos no orçamento da União com essa rubrica ficou sempre acima de $42 \%$ ao longo desse período - dando-lhe uma característica única e garantindo, também na área dos gastos públicos, uma unidade essencial entre os governos Cardoso e Lula.

Esse casamento, entre políticas econômicas ortodoxas e políticas focalizadas de combate à pobreza, veio acompanhado da redução relativa das já limitadas políticas universais. E a DRU, que garante a obtenção dos elevados superávits fiscais primários, é o instrumento fundamental que vem assegurando essa redução.

A lógica e o discurso são de que o Estado deve dirigir suas ações para os mais pobres e miseráveis conforme o estabelecimento de uma linha de pobreza minimalista, empurrando os demais para a contratação de serviços no mercado (saúde, educação e previdência, principalmente). $\mathrm{Na}$ verdade, a classe média (inclusive parte da chamada classe média baixa), há tempos supre no mercado suas necessidades (em particular com escolas e planos de saúde privados), não fazendo uso dos serviços ofertados de forma precária pelo Estado.

Desse modo, e em contrapartida, liberam-se recursos financeiros para serem direcionados para o pagamento da dívida pública, através da obtenção de elevados superávits fiscais primários. Esses superávits, obtidos sistematicamente, conforme já se viu, durante o segundo governo Cardoso e o governo Lula, vieram acompanhados de uma elevação da carga tributária de 8 pontos percentuais (de 29\% para $37 \%$ do PIB). Em suma, há uma brutal transferência de renda do conjunto da sociedade para o capital financeiro e os rentistas, em particular dos rendimentos do trabalho para o capital em geral e dos rendimentos do 'capital estritamente produtivo' (pequenos e médios) para os grandes grupos econômicos financeirizados.

Do ponto de vista político, conforme já afirmado, a política focalizada leva a uma maior fragmentação da classe trabalhadora, além de acusar os que ainda têm emprego e acesso à seguridade social de privilegiados e responsáveis pelo grau de desigualdade existente no país.

Do ponto de vista social, essa política se articula com o processo de flexibilização/precarização do trabalho, com a retirada de direitos sociais e trabalhistas, em particular saúde, educação e previdência so-

Quadro 2 - Execução do Orçamento da União - 2000-2005

\begin{tabular}{l|rrrrrrr}
\hline Orçamento Realizado & 2000 & 2001 & 2002 & 2003 & 2004 & 2005 & $2000 / 05$ \\
\hline Encargos Especiais & 42,36 & 45,52 & 45,34 & 46,82 & 43,82 & 42,45 & 44,36 \\
Gastos Sociais Totais & 43,80 & 41,22 & 40,74 & 41,91 & 44,38 & 45,28 & 43,07 \\
Outros & 13,84 & 13,26 & 13,92 & 11,27 & 11,80 & 12,27 & 12,57 \\
Total & 100,00 & 100,00 & 100,00 & 100,00 & 100,00 & 100,00 & 100,00 \\
\hline
\end{tabular}

Fonte: Relatório Resumido da Execução Orçamentária do Governo Federal em: <www.stn.fazenda.gov.br>. 
cial. Em suma, embora, em si mesmas, essas políticas de combate à pobreza reduzam, momentaneamente, as carências das populações mais miseráveis, as mesmas estão, de fato, inseridas numa lógica mais geral liberal e num programa político conservador e regressivo socialmente, próprios da nova fase por que passa o capitalismo sob hegemonia do capital financeiro ${ }^{1}$.

Assim, também na política social, o governo Lula aprofundou o modelo herdado do governo anterior, levando-o às suas últimas conseqüências. De fato, os programas sociais focalizados, tanto do ponto de vista dos montantes transferidos quanto do número de famílias atingidas, assumiram uma dimensão nunca antes vista.

O Quadro 3 apresenta as diversas áreas dos gastos sociais no período 2000-2005, segundo as suas respectivas participações relativas na parte social do Orçamento da União - excluindo desta os gastos com a previdência social, cuja maior parte é custeada pelas receitas provenientes do recolhimento de trabalhadores e empresários.
De fato, mais do que o governo Cardoso, que deu início a este tipo de política, Lula levou a sério a importância político-social das mesmas no que se refere à sua função 'amortecedora' de tensões sociais no conjunto do projeto liberal; e este é o seu objetivo essencial, pois não inclui de forma duradoura - uma vez que não tem capacidade de desarmar os mecanismos estruturais de reprodução da pobreza. De fato, apenas funcionaliza a pobreza, mantendo em permanente estado de insegurança, indigência e dependência o seu publico alvo, permitindo, assim, a sua manipulação política para objetivos estranhos aos seus reais interesses.

A relação política estabelecida é direta - presidente/eleitor -, sem mediação de partidos ou outras instituições da democracia formal, uma das características de todos os tipos de populismo (BOITO, 2004; MARQUES; MENDES, 2006). Não por acaso, as maiores votações em Lula foram nos estados em que há, absoluta ou proporcionalmente, um maior contingente de beneficiados do programa Bolsa Família.

O Bolsa Família, que unificou os programas sociais focalizados já existentes no governo Cardoso (Bol-

\section{Quadro 3 - Execução do Orçamento (social) da União - 2000-2005}

\begin{tabular}{l|rrrrrr}
\hline Orçamento Realizado & 2000 & 2001 & 2002 & 2003 & 2004 & 2005 \\
\hline Saúde & 45,20 & 46,80 & 45,62 & 44,31 & 43,46 & 42,25 \\
Educação & 23,67 & 23,04 & 23,71 & 23,20 & 19,15 & 18,75 \\
Assistência Social & 9,90 & 10,49 & 11,68 & 13,73 & 18,28 & 18,30 \\
Trabalho & 13,93 & 14,73 & 15,20 & 15,49 & 14,12 & 14,73 \\
Organização Agrária & 2,44 & 2,63 & 2,48 & 2,33 & 3,45 & 4,15 \\
Cultura & 0,53 & 0,55 & 0,43 & 0,38 & 0,43 & 0,57 \\
Desporto e Lazer & 0,39 & 0,59 & 0,48 & 0,26 & 0,36 & 0,49 \\
Habitação e Saneamento & 3,94 & 1,17 & 0,40 & 0,30 & 0,75 & 0,76 \\
Gastos Sociais Totais* & 100,00 & 100,00 & 100,00 & 100,00 & 100,00 & 100,00 \\
\hline
\end{tabular}

* Com exclusão da Previdência Social

Fonte: Relatório Resumido da Execução Orçamentária do Governo Federal em: <www.stn.fazenda.gov.br>.

Conforme se pode verificar, os gastos sociais que possuem uma maior capacidade para ter impacto estrutural no combate às desigualdades e à pobreza (saúde, educação, habitação e saneamento) perderam, ao longo do período, participação relativa no orçamento social. Em contrapartida, os gastos com a assistência social, cujo montante tem participação fundamental do Programa Bolsa Família, praticamente dobrou a sua participação no período $(9,9 \%$ para $18,3 \%$ ) - o que aponta a preocupação maior do governo Lula com a política social focalizada. Os recursos gastos com esse programa saíram de R\$ 3,3 bilhões em 2003 para R \$ 6,4 bilhões em 2005 (crescimento de $94 \%$ ) e para mais de $\mathrm{R} \$ 8$ bilhões em 2006 e 2007 (previsão). sa Escola, Bolsa Alimentação e Auxílio Gás) e o Cartão Alimentação (do Fome Zero), tem como público potencial (já alcançado em 2006) 11,2 milhões de famílias (53 milhões de pessoas) com renda per capita mensal de até R $\$ 120,00$. Aquelas consideradas extremamente pobres, com renda mensal de até $\mathrm{R} \$ 60,00$, podem participar do Programa independentemente de sua composição. Por sua vez, as famílias consideradas pobres, com renda mensal per capita entre $\mathrm{R} \$$ 60,01 e R\$120,00, podem participar do programa desde que tenham gestantes, nutrizes e crianças e adolescentes entre 0 a 15 anos. As do primeiro grupo, independentemente do número de filhos, recebem uma complementação de renda no valor de $\mathrm{R} \$ 50,00$ e as do segundo grupo no valor de $\mathrm{R} \$ 15,00$ por filho, até o 
máximo de $\mathrm{R} \$ 45,00$ (três filhos). Como as do primeiro grupo podem acumular os dois tipos de benefício, os valores pagos pelo Bolsa-Família variam de $\mathrm{R} \$ 15,00$ a R\$ 95,00 (BRASIL, 2006a)

Em suma, as famílias participantes do programa (orçamento de $\mathrm{R} \$ 8,4$ bilhões em 2006) recebem uma complementação de renda de acordo com a sua renda per capita e o número de crianças que a compõem. Como se pode constatar, a linha de pobreza é estipulada a partir de um nível de renda extremamente baixo, como condição para que os recursos transferidos sejam muito limitados - por exemplo: em 2005, o valor total destinado ao Bolsa-Família foi de, mais ou menos, R $\$ 6$ bilhões de reais (BRASIL, 2006a), enquanto a previdência social rural (de forma constitucional e permanente) destinou R\$ 17 bilhões aos trabalhadores rurais aposentados (BRASIL, 2006b) - tendo eles contribuído ou não quando em atividade -, e os juros do capital financeiro atingiram mais de $\mathrm{R} \$ 150$ bilhões de reais (BRASIL, 2006c).

Portanto, o programa não se configura como renda mínima, pois além de não ser universal, também não é constitucional e nem seu valor guarda relação com as necessidades mínimas reais de sobrevivência da família e das pessoas: o salário mínimo, de acordo com o Departamento Intersindical de Estatística e Estudos Socioeconômicos (DIEESE), deveria ser, atualmente (setembro de 2006), de R\$ 1.510 para uma família de quatro pessoas (dois adultos e duas crianças), o que daria uma renda mínima per capita de $\mathrm{R} \$$ 377,50 - mais que o triplo do valor definido como linha de pobreza pelo Bolsa Família (DIEESE, 2006).

Atualmente, o benefício médio pago, por família, é de $\mathrm{R} \$ 65,00$. Este valor, mesmo dentro da própria lógica dos programas focalizados (linhas de pobreza e indigência que subestimam as necessidades mínimas de sobrevivência), 'retira' da pobreza uma parcela muito pequena de famílias. Segundo a Pesquisa Nacional por Amostra de Domicílios (PNAD) de 2004, considerando todos os programas de transferência de renda do governo (em todos os níveis), 7 milhões de pessoas (14\% do total de pobres) 'cruzaram' a linha de pobreza e, assim mesmo, retornariam à condição anterior, imediatamente, caso os programas fossem suspensos (LAVINAS, 2006).

Por outro lado, é fato que as estatísticas sobre a distribuição de renda e a pobreza evidenciam, a par- tir do Plano Real, uma (pequena) melhora na primeira e uma redução da segunda. No entanto, faz-se necessário qualificar essa informação:

1. A distribuição de renda aludida se refere à distribuição pessoal ou familiar da renda, informada por pesquisas como a PNAD, que coleta fundamentalmente os rendimentos do trabalho, pois os rendimentos do capital (principalmente os financeiros) não são captados. O conceito de renda familiar da PNAD correspondia em 2003 a, aproximadamente, $31 \%$ da renda interna pelo conceito da contabilidade nacional. Portanto, a 'melhora' observada na distribuição de renda se deu entre os próprios trabalhadores; no mesmo período, a distribuição funcional da renda (rendimentos do trabalho versus rendimentos do capital), captada pela contabilidade nacional, mostra exatamente o contrário, os rendimentos do trabalho, como proporção da renda interna cai sistematicamente (DELGADO, 2006).

2. Embora haja uma contribuição do Bolsa Família na pequena melhora da distribuição de renda entre os trabalhadores e na redução conjuntural da pobreza, a responsabilidade maior por esses resultados se deve, fundamentalmente, aos direitos sociais básicos da seguridade social, que têm como valor de piso o salário mínimo (DELGADO, 2006; LAVINAS, 2006).

O Bolsa Família se constitui, de fato, numa política assistencialista e clientelista e, portanto, manipulatória do ponto de vista político, em particular em se tratando do seu público alvo: uma massa de miseráveis desorganizada e sem experiência associativa e de luta por seus direitos. A renda por ele transferida às famílias não se constitui num direito social, podendo ser reduzida e/ou retirada a qualquer momento, ao sabor dos interesses de cada governo - bem ao gosto da política fiscal liberalortodoxa, que não concorda com nenhuma vinculação orçamentária entre receita e despesa; com exceção, obviamente, do pagamento dos juros da dívida pública (a lei de 'Responsabilidade Fiscal' tem exatamente esse objetivo).

Por outro lado, o investimento em políticas sociais universais, que atingem o conjunto da população, tem se reduzido em termos relativos, afetando dramaticamente um enorme contingente que é pobre e tem todo tipo de carências, mas que não se beneficia dos programas 
focalizados, porque tem uma renda acima daquela estipulada pela linha de pobreza. Esse segmento se defronta, cotidianamente, com a deterioração e insuficiência dos serviços públicos universais.

Uma outra vertente (secundária) da política social, também bem ao gosto do Banco Mundial, são os programas de micro-crédito, dirigidos a determinados segmentos sociais pobres (mas não miseráveis), com o objetivo de integrá-los ao mercado. No entanto, como é praxe no Brasil, são extremamente limitados e não têm maior relevância; na verdade, são dirigidos para atividades tradicionais (precárias) que acabam não conseguindo se auto-sustentar na competição intercapitalista. Em suma, esses programas também não conseguem incluir de forma permanente e estrutural.

Em resumo, a política social do governo Lula, tal como a sua política econômica, é também de natureza liberal, coerente com o modelo econômico vigente e serve de instrumento poderoso de manipulação política de uma parcela significativa da sociedade brasileira, ao mesmo tempo em que permite um discurso 'politicamente correto'.

Apesar de tudo, das intenções e discursos governamentais, a política social no Brasil ainda tem componentes mais permanentes, que não dependem de cada governo especificamente, com impactos sociais de longo prazo e muito maiores que o Bolsa-Família. Um núcleo (direitos sociais básicos) associado à política de Estado e, portanto, ainda protegido de cortes orçamentários conjunturais e que faz parte das despesas obrigatórias, qual seja: previdência (aposentadoria e pensões dos trabalhadores), e assistência social (abono e seguro desemprego, benefícios da Lei Orgânica de Assistência Social (LOAS) e renda mensal vitalícia). Além delas, também existem outras políticas sociais básicas, de caráter setorial, em particular as de saúde e de educação, que embora sejam obrigação constitucional dos governos, inclusive com recursos vinculados no orçamento e regras específicas, não estão imunes a cortes orçamentários, conforme evidencia a existência da DRU.

$\mathrm{Na}$ verdade, essa política social institucional, derivada do Estado e inscrita na Constituição, é um empecilho para o avanço dos programas focalizados e o aumento do superávit fiscal. Por isso, está sempre na mira dos defensores das políticas focalizadas e das iniciativas de reformar a Constituição e aprofundar o ajuste fiscal - como é o caso da proposta, do ex-ministro Delfim Neto, de 'zerar' o déficit nominal. Em particular, ataca-se, sistematicamente, as aposentadorias, os benefícios da LOAS, o seguro-desemprego e a universidade pública, taxandoos como 'privilégios', mal-focalizados e dirigidos aos menos necessitados. O enfoque da focalização é tão perverso que chega a opor idosos e crianças na disputa pelos recursos públicos.

\section{Conclusão}

A eleição de Luiz Inácio Lula da Silva para a Presidência da República em 2002 representou a possibilidade de uma redefinição ou, até mesmo, uma ruptura com as políticas neoliberais. No centro da 'esperança' estava a perspectiva de superar a crise do emprego e do mercado de trabalho no país, através de um novo modelo econômico no qual a implementação de políticas de emprego e renda ocuparia um lugar central.

No entanto, o governo Lula, contrariando a origem e a história do PT, renunciou a realizar essa ruptura, negando as principais lutas e reivindicações dos trabalhadores brasileiros. Assim, incorporou plenamente, em seu discurso e em suas ações, a defesa da 'via única' para a sociedade brasileira - que vinha sendo desenvolvida pelo governo anterior e, nessa medida, passou a justificar a necessária e inexorável adaptação à 'ordem econômica mundial', diga-se à ordem do capital financeiro internacional.

É a partir dessa adesão que se pode compreender a subordinação das políticas econômicas e sociais do governo Lula à essência da lógica do capital financeiro que, para além do campo estritamente econômico, propaga-se para todas as dimensões da vida social - sustentada nas idéias-força de volatilidade e de flexibilidade, como valores e como ideologia, que passam a reger a atuação do Estado em todos os campos da sociedade.

Neste contexto, combinam-se perfeitamente a flexibilização e precarização do trabalho e as políticas focalizadas e flexíveis de combate à pobreza. Ambas regidas pela mesma lógica, qual seja, do curto prazo, do imediatismo inconseqüente, de intervenções pontuais e precárias que, para não se contrapor 'à ordem econômica neoliberal' e às determinações do Banco Mundial, subordinam-se ao reino da volatilidade, sem mudar e intervir sobre as causas estruturais dos problemas fundamentais da sociedade brasileira.

No âmbito das pesquisas da Sociologia do Trabalho, os resultados têm demonstrado, em sua imensa maioria, que a flexibilização, em suas diferentes dimensões (desregulamentação, mudanças na legislação trabalhista, diferentes formas de contrato, subcontratação/terceirização, jornadas móveis de trabalho, salários flexíveis, multifuncionalidade ou polivalência, formas de gestão e organização inspiradas no toyotismo), implicam, invariavelmente, em desemprego e precarização do trabalho.

Os dados sobre o mercado de trabalho no Brasil sob o governo Lula, embora tenham melhorado um pouco conjunturalmente, confirmam a continuidade de uma crise estrutural de emprego com a manutenção de altas taxas de desemprego. Segundo a PEDDIEESE, em média, no ano de 2005, essas taxas atin- 
giram 17\% na Região Metropolitana de São Paulo e $24 \%$ (o nível mais alto do país) na Região Metropolitana de Salvador. Neste ano, a taxa de desemprego entre os jovens de 16 a 24 anos atingiu $45 \%$ nas seis Regiões Metropolitanas do país onde a pesquisa é realizada (DIEESE, 2006). Da mesma forma, manteve-se o alto grau de informalidade, os baixos salários e a criação de ocupações precárias. $\mathrm{O}$ crescimento do emprego com carteira assinada nos últimos anos, processo que vem ocorrendo desde o ano 2000 (ainda sob o governo Cardoso), resulta, sobretudo, de um quadro econômico internacional favorável às exportações brasileiras, e não de uma política de emprego ou de uma redefinição do MLP. Processo, portanto, que não tem qualquer garantia de continuidade e que deverá, muito provavelmente, ter seu movimento invertido quando a atual fase ascendente do ciclo do comércio internacional se esgotar.

No âmbito político, a flexibilização do trabalho e a natureza flexível da política social focalizada revelam-se como estratégias eficientes para o enfraquecimento das lutas e organização dos trabalhadores, já que os divide entre privilegiados, pobres e muito pobres. Do ponto de vista social, os efeitos do programa Bolsa Família sobre a diminuição da pobreza e das desigualdades, conforme se viu, não é suficientemente esclarecido, pois acoberta o fato de que essa diminuição das desigualdades se deu em função de uma redistribuição da pobreza entre os próprios trabalhadores e não em função de uma efetiva distribuição de renda. Assim, conforme afirmam Theodoro e Delgado (2003, p. 124):

A eleição dos grupos mais pobres em detrimento de outros um pouco menos pobres pode inclusive encobrir uma perversa troca de posições entre segmentos sociais menos protegidos. Destituir 'quase-pobres' de direitos pode levá-los, num segundo momento, à condição de pobres. O risco é tanto mais grave se não se considera que muitas vezes é o acesso a direitos sociais que garante uma posição de não pobres a expressivos segmentos da população. A opção de acirramento de um embate distributivo na base, contrapondo pobres desprotegidos aos um pouco menos pobres, parece bastante perversa.

Desse modo, a permanecer a defesa e aplicação do MLP e de suas políticas sociais, o cenário para o próximo período pode ser desde já desenhado como de aprofundamento da precarização do trabalho e, conseqüentemente, dos problemas sociais, com a implementação das reformas sindical e trabalhista sob o signo da flexibilização, justificadas como inexoráveis no quadro de globalização da sociedade. Não estando também descartadas, uma nova reforma da previdência e a ampliação dos superávits primários, através do aumento do percentual da DRU.

O discurso da campanha eleitoral e as alianças eleitorais realizadas no primeiro e segundo turnos, que levaram à vitória de Lula, dando-lhe um segundo mandato, expressaram, de forma contundente, o compromisso de continuidade na sustentação desse modelo e, em especial, das políticas focalizadas que, segundo o presidente reeleito, lhe garantiram o apoio e a aprovação de seu governo pelos segmentos mais pobres da sociedade. Resta saber se os movimentos sociais e os segmentos mais organizados da sociedade brasileira aceitarão essas políticas e seus resultados perversos ou se buscarão romper com esse quadro, reafirmando a sua autonomia na busca da construção de uma sociedade alternativa em contraposição à 'via única' defendida pelo governo Lula.

\section{Referências}

ANDERSON, P. Balanço do Neoliberalismo. In: SADER, E.; GENTILLI, P. (Org.). Pós-Neoliberalismo-As políticas sociais e o Estado democrático. Rio de Janeiro: Paz e Terra, 1995, p. 9-23.

BANCO MUNDIAL. Poverty Reduction and Growth: Virtous and Vicious Circles. Washington, 2006.

BOITO, A. Relações de classe na nova fase do neolibe-ralismo brasileiro. In: IV CONGRÈS MARX INTER-NATIONAL. Universidade de Paris. Anais. Paris, set./out. 2004.

BRASIL. Ministério do Desenvolvimento Social e Combate à Fome. Programa Bolsa Família. Disponível em <http:// www.mds.gov.br/bolsafamilia>. Acesso em: out. 2006a.

Ministério da Previdência Social. Legislação. Dis-

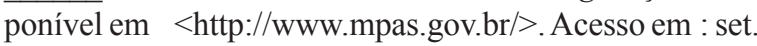
2006 b.

Banco Central do Brasil. Disponível em <www. bcb.gov.br >. Acesso em: set. 2006c.

CASTEL, R. Les métamorphoses de la question sociale. Une chronique du salariat. Paris: Fayard, 1995.

DELGADO, G. Melhorias na distribuição de renda: falácias, meias verdades e dados de realidade.Dados sobre Economia e Distribuição de Renda, Lista Grupo Economistas. Disponível em <crbrasileira@uol.com.br>. Acesso em: 26 jun. 2006.

DIEESE. A ocupação dos jovens nos mercados de trabalho metropolitanos. Estudos e Pesquisas - Dieese, São Paulo, ano 3, n. 24, set. 2006. 
DONZELOT, J. L'Invention du social. Paris: Fayard, 1994.

FILGUEIRAS, L. O Neoliberalismo no Brasil: estrutura, dinâmica e ajuste do Modelo Econômico. In: MASUALDO, B.; ARCEO, E. (Org.) Neoliberalismo y sectores dominantes - tendências globales y experiências nacionales, Buenos Aires: CLACSO, 2006a, p. 179-206. (Colección Grupos de Trabajo).

História do Plano Real. São Paulo: Boitempo, $2006 \mathrm{~b}$.

IVO, A. L. A "destituição" do social: Estado, governo e políticas sociais, Caderno CRH, Salvador, n. 35, p. 41-84, jul./dez. 2001.

LAVINAS, L. Transferir renda para quê ? Globo Online, São Paulo, 11 ago. 2006. Disponível em <www.globo.com>. Acesso em: set. 2006.

MARQUES R. M.; MENDES, A. O social no governo Lula: a construção de um novo populismo em tempos de aplicação de uma agenda neoliberal. Revista de Economia Política, São Paulo, v. 267, n.1, p. 58-74, jan./mar. 2006.

MOTA, E. A Cidadania do Fordismo. Revista História e Perspectivas, Uberlândia, v. 5, p. 71-83, 1991.

SALAMA, P. Le Défi des Inégalites - Amérique Latinel Asie : une comparaison économique. Paris, La Découverte, 2006.

THEODORO, M.; DELGADO, G. Política Social: universalização X focalização - subsídios para o debate, Politicas sociais - acompanhamento e análise, IPEA, Rio de Janeiro, p. 122-126, ago. 2003.

\section{Nota}

1 Naverdade, esses programas podem também, eventualmente, serimplementados num outro contexto, no interior de um outro modelo econômico e com um outro bloco de poder - numa perspectiva claramente emergencial earticulados compolíticas estruturais-, mas aí perderiam o seu caráter focalizado estrito.

\section{Graça Druck}

Doutora em Ciências Sociais pela Univ. Estadual de Campinas (UNICAMP)

Pesquisadora do Centro de Recursos Humanos (CRH-UFBA) e do CNPq

Professora na Faculdade de Filosofia e Ciências Humanas da UFBA - Centro de Recursos Humanos

Rua Caetano Moura, 99 - 1. subsolo

Federação

Salvador - Bahia

CEP : 40223-360

\section{Luiz Filgueiras}

Doutor em Economia pela UNICAMP

Bolsista da CAPES, em estágio Pós-Doutoral na Universidade Paris-XIII

Professor na Faculdade de Ciências Econômicas da UFBA

Praça Treze de Maio, 06 - 5. andar, sala 500

Piedade, Centro

Salvador - Bahia

CEP: 40070-010 